\title{
Avaliação de equações para estimar o consumo de vacas leiteiras
}

\author{
Evaluation of equations for estimating the consumption of dairy cows
}

\author{
ZANIN, Ediane ${ }^{1}$; HENRIQUE, Douglas Sampaio ${ }^{2 *}$; FLUCK, Ana Carolina ${ }^{2}$
}

\author{
${ }^{1}$ Universidade Estadual de Londrina, Programa de Pós-Graduação em Ciência Animal, Londrina, Paraná, \\ Brasil. Bolsista CAPES. \\ ${ }^{2}$ Universidade Tecnológica Federal do Paraná, Programa de Pós-Graduação em Zootecnia, Dois Vizinhos, \\ Paraná, Brasil. \\ *Endereço para correspondência: douglas@utfpr.edu.br
}

\section{RESUMO}

Objetivou-se com este estudo realizar uma comparação do poder de predição de diferentes equações do consumo de matéria seca de vacas leiteiras. O trabalho foi conduzido por meio de pesquisas na literatura coletando informações sobre massa corporal, produção de leite, dias de lactação, consumo de matéria seca e teor de gordura no leite de vacas leiteiras criadas no Brasil. Todas essas informações, menos o consumo de matéria seca observado, foram utilizadas para calcular o consumo de matéria seca predito com as equações dos modelos: National Research Council (NRC, 2001), Cornell Net Carbohydrate and Protein System (CNCPS, 2004), Agricultural and Food Research Council (AFRC, 1993) e De Freitas et al. (2006). Posteriormente, as estimativas das equações foram usadas para avaliar o poder de predição dos modelos por meio da comparação gráfica dos seus resíduos padronizados conforme Draper \& Smith (1966) e Montgomery (2005) e do critério de Akaike (AKAIKE, 1974). Para os dados analisados neste estudo, o NRC (2001) foi considerado como melhor escolha por apresentar o $\mathrm{ER}_{\mathrm{r}}=1$. Os demais, apresentaram $\mathrm{ER}_{\mathrm{r}}$ maior do que 20 e, portanto, não foram adequados para a predição do CMS. O modelo AFRC (1993) apresentou tendência a subestimar os valores preditos com $76 \%$ dos pontos acima da linha de nulidade.

Palavras-chave: bovinocultura de leite, consumo predito, formulações de dietas, nutrição de ruminantes

\section{SUMMARY}

The present study aimed to perform a comparison of the predictive power of different equations to estimate intake by dairy cows. The work was conducted through collecting information in literature about body weight, milk yield, days in milk, dry matter intake and fat content of milk of dairy cows raised in Brazil. All this information, with the exception of dry matter intake, were used to predict the dry matter intake with equations of the model: National Research Council (NRC, 2001), Cornell Net Protein and Carbohydrate System (CNCPS, 2004), Agricultural and Food Research Council (AFRC, 1993) and De Freitas et al. (2006). Subsequently, the predictive power of the mathematical equations was compared through the graphical comparison of the standard as Draper and Smith (1966) and Montgomery (2005) and by means of Akaike's criterion (Akaike, 1974) waste. NRC (2001) was the best choice for presenting the $\mathrm{ER}_{\mathrm{r}}=1$, all others showed $E R_{r}$ much greater than 20 and therefore must be considered worse choices. AFRC (1993) has tended to underestimate the predicted values with $76 \%$ points above the line of invalidity. Model NRC (2001) is the one that best predicts the dry matter intake of dairy cows under the conditions studied.

Key words: dairy cattle, intake prediction, diet formulation, ruminant nutrition 


\section{INTRODUÇÃO}

O consumo de matéria seca (CMS) afeta diretamente fatores produtivos, principalmente na bovinocultura de leite, em que é neccessário atingir níveis ótimos de produção e reprodução. Segundo Mertens (1987), o CMS pode corresponder de 60 a $90 \%$ das variações no desempenho dos bovinos e somente de 10 a $40 \%$ do restante são relacionados a variações na qualidade nutricional dos alimentos. Uma das principais discussões na bovinocultura de leite é se a produção de leite é influenciada pelo CMS ou, de forma contrária, o CMS é influenciado pela produção (NRC, 2001).

Atualmente, existem diversos modelos matemáticos que podem predizer $\mathrm{o}$ CMS e tornar a produção mais sustentável. Conforme Dumas et al. (2008), a modelagem matemática utiliza equações para descrever ou simular processos em um sistema e pode ser uma ferramenta para extrair maiores informações sobre a ingestão do alimento. Entretanto, existe uma falta de precisão nas equações de predição do CMS, provavelmente devido ao manejo, dieta, animal e ambiente onde o modelo foi desenvolvido (McMENIMAM et al., 2009).

Para bovinos de leite, os modelos mais utilizados são Cornell Net Carbohydrate and Protein System (CNCPS-FOX et al., 1992; TYLUTKI et al., 2008) e National Research Council (NRC, 1989; 2001), ambos norte-americanos, empregando informações de regiões de clima temperado, animais da raça holandesa e alimentos característicos do sistema de produção norte-americano. Enquanto o CNCPS estima as exigências a partir da produção de leite e da massa do animal, o NRC utiliza também dados sobre a composição do leite e a semana de lactação.

Outro modelo amplamente utilizado é o Agriculture and Food Research Council (AFRC, 1993), desenvolvido em diferentes centros de pesquisa do Reino Unido, região de clima temperado. Seu modelo consiste em análise de regressão múltipla, utilizando o banco de dados onde a base principal da alimentação é silagem de gramíneas (SOUZA et al., 2014).

$\mathrm{O}$ modelo desenvolvido por Freitas et al. (2006) em condições tropicais pode se adequar melhor à realidade dos sistema de produção de leite brasileiro. $\mathrm{O}$ mesmo baseia-se em regressão múltipla com variáveis que afetam o consumo.

Apesar do enriquecimento científico em pesquisas para bovinos de leite, estudos em condições tropicais para a predição do CMS são escassos. Deste modo, o presente trabalho teve por objetivo realizar uma comparação do poder de predição das principais equações vigentes para estimar o consumo de vacas leiteiras.

\section{MATERIAL E MÉTODOS}

Informações sobre massa corporal, produção de leite, dias de lactação, consumo de matéria seca e teor de gordura no leite de vacas, podem ser observados na Tabela 1.

Para a compilação de dados, foram selecionados trabalhos realizados no Brasil, em condições tropicais e que possuíssem todos os pré-requisitos dos quatro modelos de predição do CMS pré-escolhidos, procurando descrição completa das dietas, CMS, produção de leite, porcentagem de gordura do leite, dias de lactação e média da massa corporal. Foram utilizados 24 trabalhos, 
sendo 18 artigos publicados entre 19982013, três dissertações entre 2007-2012 e três teses de 2005-2012. No total, foram 303 animais e, destes, foram selecionados 100, os quais contemplavam todas as informações exigidas. Os grupamentos genéticos foram compostos por $56 \%$ de vacas da raça Holandesas, 3\% vacas da raça Jersey, 3\% de vacas mestiças Holandês x Jersey, 24\% Holandês x Zebu e 13\% Holandês x Gir. As dietas bases foram compostas, majoritariamente, por silagem de milho (46\% dos tratamentos empregados), capim elefante (16,7\%), cana-de-açúcar $(12,5 \%)$ e as demais compostas por palma forrageira, capim bermuda var. Tifton e silagens de sorgo e cana de açúcar.

Todas estas informações, com exceção do consumo de matéria seca observado, foram utilizadas para calcular $o$ consumo de matéria seca predito, utilizando os modelos de estimativa de consumo:

Modelo NRC (2001): CMS = 0,372×LCG+0,0968×MC $\mathrm{MC}^{0,75} \times\left\{1-\mathrm{e}^{[-0,192 \times(\mathrm{SL}+3,67)]}\right\}$

onde:

CMS = consumo de matéria seca, $\mathrm{kg} / \mathrm{d}$;

LCG = leite corrigido para $4 \%$ de gordura;
$\mathrm{MC}=$ massa corporal, $\mathrm{kg}$;

$\mathrm{SL}=$ semana de lactação, dias;

$\mathrm{e}=$ base dos logaritmos naturais.

Modelo CNCPS - adaptada de Fox et al. (2004): CMS=0,0185×MC $\times 0,95 \times \mathrm{LC}$

onde:

CMS = consumo de matéria seca, $\mathrm{kg} / \mathrm{d}$;
LCG = leite corrigido para $4 \%$ de gordura;

$\mathrm{MC}=$ massa corporal, $\mathrm{kg}$;

Modelo AFRC (1993): $\mathrm{MS}=0,076+0,404 \times \mathrm{CC}+0,013 \times \mathrm{MC}-0,129 \times \mathrm{SL}+4,12 \times \log (\mathrm{SL})$ $+0,14 \times \mathrm{PL}$

onde:

$\mathrm{CMS}=$ consumo de matéria seca, $\mathrm{kg} / \mathrm{d}$;

$\mathrm{CC}=$ consumo de concentrado, $\mathrm{kg} / \mathrm{d}$;

$\mathrm{MC}=$ massa corporal, $\mathrm{kg}$;
$\mathrm{SL}=$ semana de lactação, dias;

Log $=$ logaritmo na base 10 ;

$\mathrm{PL}=$ produção de leite, $\mathrm{kg} / \mathrm{d}$.

Modelo Freitas et al. (2006): $\mathrm{CMS}=-100+0,116 \times \mathrm{MC}+2,91 \times \mathrm{PL}+22,8 \times \mathrm{G}-2,6 \times \mathrm{G}^{2}$ $0,00483 \times \mathrm{MC} \times \mathrm{PL}$

onde:

CMS $=$ Consumo de matéria seca, $\mathrm{kg} / \mathrm{d}$;

$\mathrm{MC}=$ massa corporal, $\mathrm{kg}$;

$\mathrm{PL}=$ produção de leite, $\mathrm{kg} / \mathrm{d}$.

$\mathrm{G}=$ teor de gordura no leite, $\%$.

Os modelos NRC (2001) e CNCPS (2004), requerem de correção da gordura do leite para 4\%. Para isso, foi utilizada a equação proposta no NRC
(2001) para a correção dos dados descritos na Tabela 1:

$\mathrm{LCG}=0,4 \mathrm{x}$ Produção $+15 \mathrm{x}$ \%GOR/100 x Produção.

onde:

LCG = Leite corrigido para $4 \%$ de gordura em kg/d

Produção = produção de leite em $\mathrm{kg} / \mathrm{d}$ $\% \mathrm{GOR}=$ porcentagem de gordura do leite 
Rev. Bras. Saúde Prod. Anim., Salvador, v.18, n.1, p.76-88 jan./mar., 2017

Tabela 1. Valores médios dos dados utilizados para calcular o CMS predito

\begin{tabular}{|c|c|c|c|c|c|c|}
\hline $\mathrm{MC}$ & PL & $\mathrm{G}$ & & $\mathrm{CMS}_{\mathrm{O}}$ & & \\
\hline$\overline{\mathrm{Kg}}$ & $\mathrm{kg} / \mathrm{d}$ & $\%$ & Dias de lactaçao & $\mathrm{kg} / \mathrm{d}$ & Referencias & Natureza \\
\hline 471 & 23,8 & 3,4 & 97 & 17,4 & Chagas, 2012 & Dissertação \\
\hline 616 & 33,6 & 3,6 & 123 & 22,6 & Corrêa et al. 2003 & Artigo \\
\hline 587 & 19,1 & 3,4 & 154 & 18,1 & Costa et al. 2005 & Artigo \\
\hline 585 & 31,2 & 3,1 & 35 & 17,0 & Filho, 2009 & Dissertação \\
\hline 568 & 23,9 & 3,1 & 106 & 19,4 & Fontaneli, 2005 & Tese \\
\hline 486 & 16,5 & 3,7 & 270 & 7,9 & Fruscalso, 2007 & Dissertação \\
\hline 537 & 16,2 & 4,1 & 95 & 15,3 & Leggi et al. 1998 & Artigo \\
\hline 494 & 9,9 & 4,2 & 190 & 13,3 & Lopes, et al. 2005 & Artigo \\
\hline 516 & 15,3 & 3,5 & 141 & 14,3 & Martinez, 2008 & Tese \\
\hline 616 & 18,5 & 3,4 & 91 & 18,6 & Melo et al. 2003 & Artigo \\
\hline 511 & 19,9 & 3,8 & 57 & 15,7 & Mendonça etal.2004 & Artigo \\
\hline 584 & 24,2 & 3,1 & 45 & 18,4 & Neto et al. 2013 & Artigo \\
\hline 456 & 18,9 & 4,4 & 38 & 15,8 & Oliveira et al. 2001 & Artigo \\
\hline 578 & 19,7 & 3,8 & 176 & 19,4 & Oliveira et al. 2007 & Artigo \\
\hline 558 & 26,1 & 4,1 & 25 & 18,8 & Pereira et al. 2005 & Artigo \\
\hline 526 & 15,9 & 3,3 & 85 & 13,3 & Pires et al. 2010 & Artigo \\
\hline 514 & 15,1 & 3,8 & 30 & 16,6 & Ramalho et al. 2006 & Artigo \\
\hline 588 & 31,8 & 4,4 & 30 & 16,0 & Santos et al. 2009 & Artigo \\
\hline 466 & 12,3 & 3,7 & 100 & 12,8 & Santos et al. 2012 & Artigo \\
\hline 500 & 21,4 & 4,3 & 84 & 14,0 & Silva et al. 2001 & Artigo \\
\hline 538 & 20,7 & 3,8 & 101 & 16,8 & Soares et al. 2004 & Artigo \\
\hline 558 & 9,7 & 3,4 & 110 & 13,6 & Costa et al. 2009 & Artigo \\
\hline 422 & 7,2 & 3,5 & 45 & 6,7 & Vilela et al. 2003 & Artigo \\
\hline 421 & 19,8 & 3,5 & 85 & 18,7 & Wilbert, 2012 & Tese \\
\hline
\end{tabular}

Posteriormente, os dados foram utilizados para avaliar o poder de predição das equações por meio da comparação gráfica dos seus resíduos padronizados conforme Draper \& Smith (1966) e Montgomery (2005) e por meio do critério de Akaike corrigido $\mathrm{AIC}_{\mathrm{cr}}$ (AKAIKE, 1974).

Os critérios de avaliação dos modelos foram baseados nos descritos pelos autores Burnham \& Anderson (2004) e Vieira et al. (2012). Para realizar a seleção dos modelos foi calculada a diferença entre o $\mathrm{AIC}_{\mathrm{cr}}$ dos modelos e o $\mathrm{AIC}_{\mathrm{cr}}$ mínimo do rol de modelos $\left(\Delta_{\mathrm{r}}\right)$; a probabilidade de verossimilhança $\left(\mathrm{w}_{\mathrm{r}}\right)$ a partir do $\Delta_{\mathrm{r}}$ e do número de modelos e a verossimilhança relativa $\left(E_{r}\right)$ Para serem considerados semelhantes em reproduzir o comportamento dos dados e reduzir a perda de informação, os valores de $\Delta_{\mathrm{r}}$ deveriam estar entre 0 e 2 (a preferência deve ser ao modelo com o menor número de parâmetros). Valores de $\Delta_{\mathrm{r}}$ maiores que 2 e menores ou iguais a 10, significavam que o desempenho do modelo foi razoável e valores maiores que 10 indicam que o modelo foi falho no objetivo.

Para avaliação, ainda foi levado em consideração as indicações de Vieira et al. (2012), que sugerem que quando o valor do $\mathrm{w}_{\mathrm{r}}$ for superior a 0,8 deve ser considerado que o modelo é uma representação verossímil da realidade, sendo intermediária quando $\mathrm{w}_{\mathrm{r}}$ é maior que 0,5 e menor ou igual a 0,8 e não verossímil quando $\mathrm{w}_{\mathrm{r}}$ for menor ou igual a 0,5. Na escolha do melhor modelo, aquele que possuir o valor de $E_{\mathrm{r}}=1$ será a melhor escolha, os modelos cujos valores de $E_{\mathrm{r}}$ forem 
maiores que 1 e menores ou iguais a 20 serão considerados modelos menos prováveis e aqueles cujo $\mathrm{ER}_{\mathrm{r}}$ superar o valor 20 serão as piores escolhas.

\section{RESULTADOS E DISCUSSÃO}

Para os dados analisados, somente o modelo do NRC (2001) apresentou valor de $\Delta_{\mathrm{r}}$ entre 0 e 2 (Tabela 2). Os demais modelos analisados não foram equivalentes ao modelo do NRC para o comportamento observado. Com relação ao $\mathrm{W}_{\mathrm{r}}$, os valores maiores que 0,8 são considerados uma representação verossímil da realidade, no qual somente o modelo proposto pelo NRC apresentou esse resultado. Como o $\mathrm{w}_{\mathrm{r}}$ dos demais modelos apresentaram valores abaixo de 0,5 ; esses não foram considerados verossímeis (BURNHAM \& ANDERSON, 2004; VIEIRA et al., 2012).

Tabela 2. Resultados das avaliações dos modelos propostos

\begin{tabular}{lcccc}
\hline Modelos & AICcr & $\Delta \mathrm{r}$ & $\mathrm{Wr}$ & $\mathrm{ERr}$ \\
\hline NRC (2001) & 214 & 0,0 & 0,99 & 1,0 \\
CNCPS adaptado de Fox et al. (2004) & 237 & 23,0 & $1,04.10^{-5}$ & 96.406 \\
AFRC (1993) & 230 & 15,8 & $3,63.10^{-4}$ & 2.750 \\
Freitas et al. (2006) & 235 & 20,6 & $3,40.10^{-5}$ & 29.380 \\
\hline
\end{tabular}

$\mathrm{AIC}_{\mathrm{Cr}}=$ critério de Akaike corrigido; $\Delta_{\mathrm{r}}=$ diferença entre AICcr; $\mathrm{w}_{\mathrm{r}}=$ probabilidade de verosimilhança; $\mathrm{ER}_{\mathrm{r}}=$ verrosimilhança relativa.

A análise gráfica dos resíduos padronizados (Figura 1) confirmou a superioridade do modelo NRC (2001) para os dados analisados, não apresentando tendência, o que indica que não há correlação entre os valores preditos e os resíduos padronizados, enquanto os outros modelos apresentaram heterogeneidade de variâncias.

Apesar do modelo publicado pelo NRC ter sido considerado a melhor escolha nesse trabalho, Jardim et al. (2012) concluiu que o NRC (2001) prediz o CMS com exatidão, porém, necessita de alguns ajustes visando melhor aplicabilidade na predição do CMS em condições de climas tropicais, principalmente nos períodos chuvosos do ano em que o teor de umidade e fibra do pasto aumenta, influenciando no consumo.

Quando se trata de alimentos forrageiros frescos, a exatidão e predição no CMS perde confiança, pela inconstância da composição de teores nutritivos. Fukumoto et al. (2010) relatam que a redução do CMS pode estar relacionada com o avanço do estágio de lactação, oscilando as exigências do animal.

No caso do modelo CNCPS (2004), foi observada tendência não linear quadrática de variação dos resíduos em função dos valores preditos. Já o modelo AFRC (1993) apresentou tendência a subestimar os valores preditos $(76 \%$ dos pontos se encontram acima da linha de nulidade), enquanto o NRC (2001) apresentou distribuição aleatória, com $51 \%$ dos pontos acima e $49 \%$ abaixo da linha de nulidade. Em última análise, o modelo sugerido por Freitas et al. (2006) teve uma tendência linear negativa dos resíduos padronizados em função dos valores preditos. 
NRC, 2001
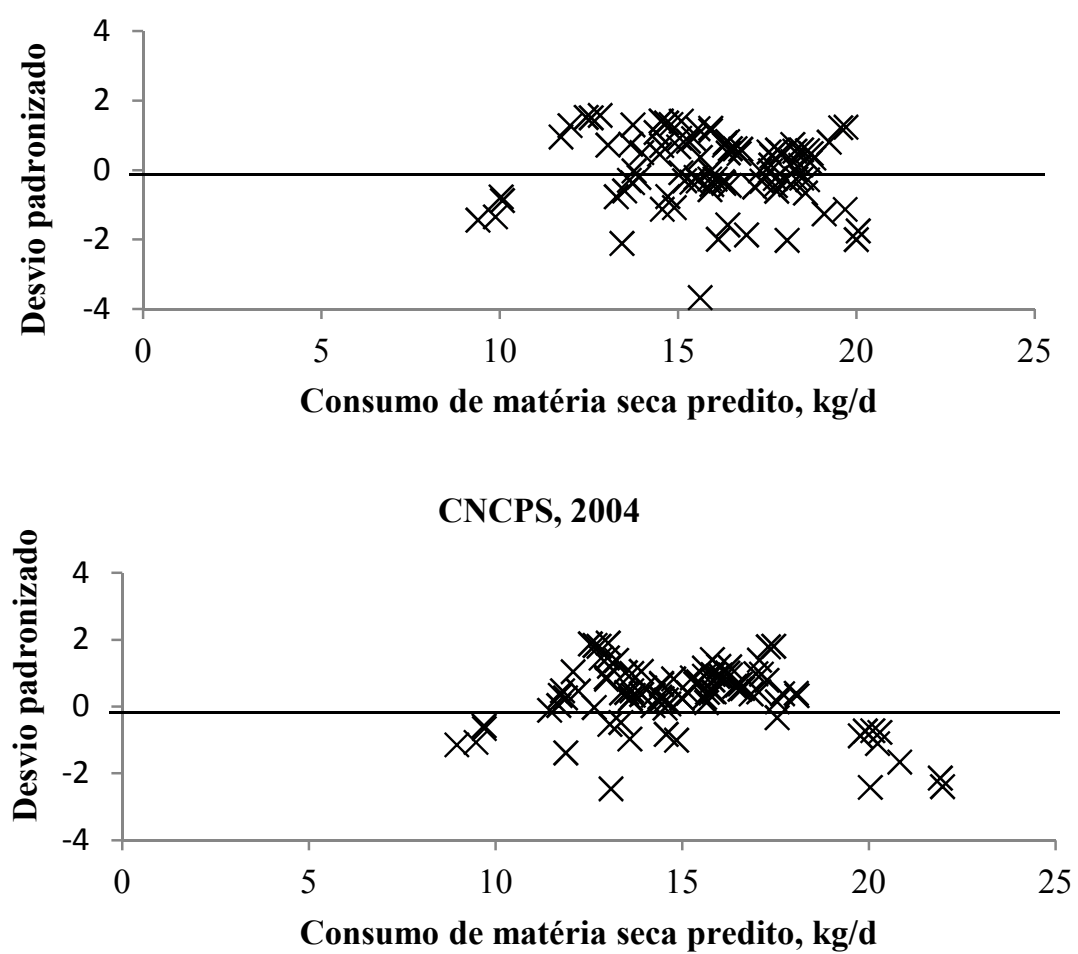

AFRC, 1993

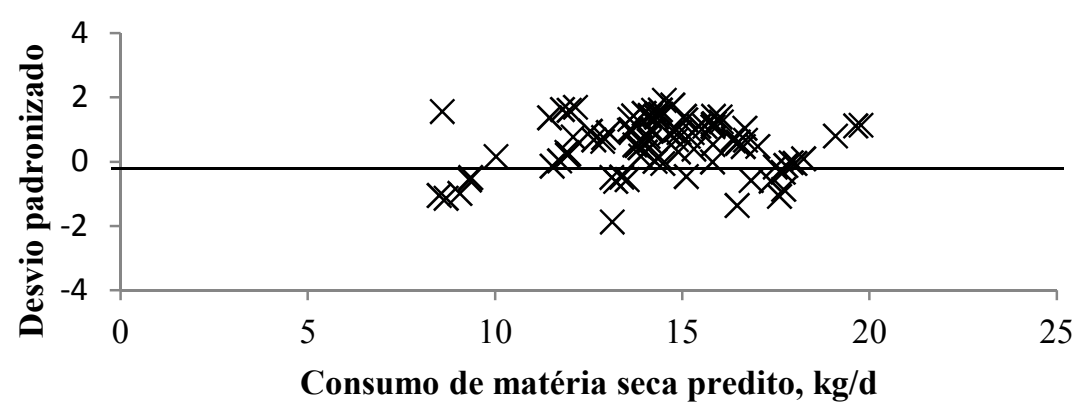

FREITAS et al., 2006

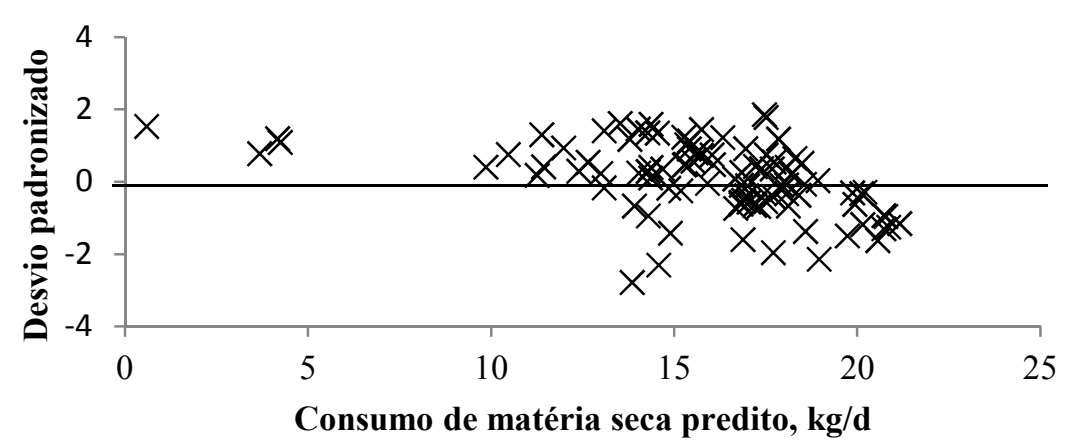

Figura 1. Desvios padronizados dispersos em função do CMS predito modelos 
$\mathrm{O}$ número de parâmetros dos modelos avaliados é diferente. O modelo NRC possui cinco parâmetros, o CNCPS quatro parâmetros e os modelos AFRC e Freitas et al. (2006) possuem sete parâmetros, incluindo o parâmetro relativo ao erro aleatório. Apesar do número de parâmetros, o modelo NRC apresentou o melhor desempenho para predizer o consumo de matéria seca de vacas leiteiras nas condições brasileiras, pois é composto por parâmetros que quantificam fatores importantes na variação do consumo como: massa corporal, semana de lactação e produção de leite corrigido para $4 \%$ de gordura permitindo maior exatidão na predição do CMS.

Os modelos CNCPS e Freitas et al., não possuem parâmetro que considere tempo de lactação, um fator importante já que consumo varia de acordo com o período em que o animal lactante se encontra. Nos primeiros dias de lactação o CMS é baixo devido às adaptações metabólicas que ocorrem entre o pós-parto e o início da lactação, depois ele aumenta para acompanhar o acréscimo nas demandas nutricionais devidas à produção leiteira $\mathrm{e}$ diminuiu no final da lactação em decorrência da redução na produção de leite (NRC, 2001; FISCHER et al., 2002). Apenas o modelo AFRC apresenta um parâmetro relacionado à dieta, ou seja, o CC (consumo de concentrado). Mertens (1987) relata que o CC pode indicar de forma indireta a quantidade de fibra que a vaca está ingerindo, pois os alimentos concentrados possuem menos fibra do que os volumosos e, a ingestão inadequada de fibra pode causar doenças metabólicas (acidose) e redução na gordura do leite, quando há escassez de fibra na dieta e limitação de consumo nos casos em que fibra em excesso ou de baixa qualidade é ingerida pelos ruminantes. Esse mesmo autor cita que o consumo de fibra irá influenciar no CMS, sendo correlacionadas negativamente.
Corroborando, Allen (2000) descreve que fatores ligados ao alimento estão diretamente ligados ao CMS, como a fonte e a digestibilidade da FDN e o tamanho de partícula do alimento.

Equações contendo os fatores dietéticos são mais utilizadas para avaliar pós consumo em vez de prever o que será consumido (NRC, 2001). Contudo, a consideração do teor de fibra no alimento, possibilita uma melhor formulação de ração levando-se em conta que alimentos com lenta taxa de digestão da fibra provocam limitação do consumo, pelo efeito do enchimento, restringindo assim a quantidade necessária que deveria ser ingerida para suprir as demandas do animal.

Todos os modelos avaliados apresentaram o parâmetro massa corporal (MC) evidente, sendo o mais importante ao se tratar de balanceamentos de dietas, já que as vacas modificam constantemente $\mathrm{O}$ peso corporal durante o período de lactação e consequentemente o consumo de matéria seca também é modificado. Rennó et al. (2006) descreveram que perdas de massa corporal média de vacas leiteiras de $77 \mathrm{~kg}$ após o parto devido à expulsão da placenta, feto e demais conteúdos uterinos. Essa perda se caracteriza também pelo intenso catabolismo das reservas corporais no fornecimento de energia para produção de leite.

Outro fator importante na predição de CMS é a produção de leite, que é considerada em todos os modelos avaliados. Diversos autores encontraram relação direta entre a produção de leite e o CMS (ALVIM et al., 1999; EIFERT et al., 2006; GOMIDE et al., 2001; SANTOS et al., 1998; SOUSA, 2009; VASORI et al., 1995). Ainda Berman (2011), cita que algumas peculiaridades fisiológicas ligadas ao grupamento genético podem interferir no CMS, como 
a baixa resposta dos zebuínos a mudança de manejo e nutrição.

Segundo NRC (1996) não existem equações que podem ser usadas em todas as situações de produção, seria necessário desenvolver equações de predição de CMS para situações específicas e assim obter melhor resposta. Diante disso, há uma grande necessidade de desenvolver e validar modelos para predizer o CMS que sejam mais precisos e ajustados para as diversas regiões brasileiras.

Diante do exposto, o desenvolvimento de um modelo mecanicista que leve em consideração os principais fatores que influenciam o consumo, relativos não apenas ao animal, mas também à dieta $\mathrm{e}$ ao ambiente, possa reduzir a necessidade de criar um modelo para cada situação. Esse modelo teria ampla aplicabilidade, mas teria como limitações a serem vencidas: sua operacionalização matemática e a obtenção de dados confiáveis para serem utilizados como entrada no modelo.

Para os dados analisados neste estudo, o NRC (2001) foi considerado como melhor escolha por apresentar o $\mathrm{ER}_{\mathrm{r}}=1$. Os demais, apresentaram $\mathrm{ER}_{\mathrm{r}}$ maior do que 20 não sendo adequados para a predição do CMS. O modelo AFRC (1993) apresentou tendência a subestimar os valores preditos com $76 \%$ dos pontos acima da linha de nulidade.

\section{REFERÊNCIAS}

\section{AGRICULTURAL AND FOOD}

REASERCH COUNCIL. Energy and protein requirements of ruminants. Oxon: CAB international, 159 p.1993.

AKAIKE, H. A new look at the statistical model identification. IEEE Transactions on Automatic Control, v.19, n.6, p.716-23.1974.
ALLEN, M.S. Effects of diet on shortterm regulation of feed intake by lactating dairy cattle. Journal of Dairy Science, v.83, p.1598-1624, 2000.

\section{ALVIM, M.J.;VERNEQUE, R.S.; VILELA, D.; CÓSER, A.C.; BOTREL, M.A.; REZENDE, G.M.Estratégia de fornecimento de concentrado para vacas da raça holandesa em pastagem de coast- cross. Pesquisa Agropecuária}

Brasileira, v.34, n.9, p.1711-1720, 1999.

BERMAN, A.. Invited review: Are adaptations presente to support dairy cattle productivity in warm climates?

Journal of Dairy Science, v.94, p.21472158, 2011.

BURNHAM, K.P.; ANDERSON, D.R. Multimodel inference understanding AIC and BIC in model selection. Sociological Methods and Research, v.33, p.261-304, 2004.

\section{CHAGAS, J.L. Teor de proteína no} concentrado de vacas no terço inicial de lactação, mantidas em pasto de capim elefante. 2012. 81f. Dissertação (Mestrado em Ciências) - Universidade de São Paulo, Piracicaba.

CORRÊA, E.S.C.; NEVES, M.; OLIVEIRA, G.S.; RAMOS, H.M.Desempenho de vacas holandesas alimentadascom cana-de-açúcar ou silagens de milho de diferentes textura de grão. Scientia Agricola, v.60, n.4, p.621629, 2003.

COSTA, M.G.; CAMPOS, S.M.J.; FILHO,V, C.S.; DINIZ, F.R.; MENDONÇA, S.S.; SOUZA, P.D.; TEIXEIRA, P.M. Desempenho produtivo de vacas leiteiras alimentadas com diferentes proporções decana-de-açúcar e concentrado ou silagem de milho na dieta. Revista Brasileira de Zootecnia, v.34, n.6, p.2437-2445, 2005. 
COSTA, T.L.; VELOSO, M.C.; PIRES, V.J.A.; NETO, R.L.A. BONOMO, P.; MENDES, L.B.F.; OLIVEIRA, S.J.; AZEVEDO, T.S.; SILVA,L. V. Teores de concentrado em dietas a base de cana-de-açúcar para vacas mestiças em lactação. Revista Brasileira de Saúde e Produção Animal, v.10, n.4, p.10191031, 2009.

DRAPER, N.R.; SMITH, H. Applied regression analysis. New York: John Wiley \& Sons, 1966. p.407.

DE FREITAS, A.J.; LANA, P.R.; RODRIGUEZ, M.L.A.; SOUZA, J.C. Predição e validação do desempenho de vacas de leite nas condições brasileiras.

Arquivo Latino Americano de Produção Animal, v.14, p.120-134, 2006.

DUMAS, A.J.; DIJKSTRA, J.; FRANCE J.. Mathematical modelling in animal nutrition: a centenary review. Journal of Agricultural Science, v.146, p.123-142, 2008.

EIFERT, C. E.; LANA, P.R.; LANNA, D.P.D.; LEOPOLDINO, M.W.; OLIVEIRA, M.V.M.; ARCURI, B.P.; CAMPOS, S.M.J.; LEÃO, I.M.; FILHO, V.C.S. Consumo, produção e composição do leite de vacas alimentadas com óleo de soja e diferentes fontes de carboidratos na dieta. Revista Brasileira de Zootecnia, v.35, n.1, p.211-218, 2006.

FOX, G.D.; TEDESCHI, O.L.; TYLUTKI, T.P.; RUSSELL, J.B.;VAN AMBURGH, M.E.; CHASE, L.E.; PELL, A.N.; OVERTON, T.R.The cornell net carbohydrate and protein system model for evaluating herd nutrition and nutrient excretion. Animal Feed Science and Technology, v.112, p.29-78, 2004.
FILHO, M.M. Desempenho produtivo e reprodutivo e parâmetros sanguíneos de vacas leiteiras alimentadas com diferentes fontes de gordura no período de transição e inicio de lactação. 2009. 102f. Dissertação (Mestrado em Medicina Veterinária) - Programa de Pósgraduação em Nutrição e Produção Animal - Universidade de São Paulo, Pirassununga.

FISCHER, V.; DESWYSEN, G.A.; DUTILLEUL, P.; BOEVER, J.Padrões da distribuição nictemeral do comportamento ingestivo de vacas leiteiras, ao Início e ao final da lactação, alimentadas com dieta à base de silagem de milho. Revista Brasileira de Zootecnia, v.31, p.2129-2138, 2002.

FONTANELI, S.R.Produção de leite de vacas Holandesas em pastagens tropicais perenes no planalto médio do Rio Grande do Sul. 2005. 193f. Tese (Doutorado em Zootecnia) Programa de Pós-graduação em Zootecnia -Universidade Federal do Rio Grande do Sul, Porto Alegre.

FRUSCALSO, V.Influência da oferta da dieta, ordem e estádio de lactação sobre as propriedades físico-químicas e microbiológicas do leite bovino e a ocorrência de leite instável não ácido. 2007. 147f. Dissertação (Mestrado em Zootecnia), Programa de Pós-graduação em Zootecnia - Universidade Federal do Rio Grande do Sul, Porto Alegre.

FUKUMOTO, N. M., J. C. DAMASCENO, F. DERESZ, C. E. MARTINS, A. C. CÓSER, SANTOS, G.T.. Milk yield and composition, feed intake and stocking rate of crossbread cows in tropical grasses managed in a rotational grazing system. Revista Brasileira de Zootecnia, v.39, p.15481557, 2010. 
GOMIDE, A.J.; WENDLING, J.I.; BRAS, P.S.; QUADROS, B.H.Consumo e produção de leite de vacas mestiças em pastagem de Brachiaria decumbens manejada sob duas ofertas diárias de forragem.

Revista Brasileira de Zootecnia, v.30, n.4, p.1194-1199, 2001.

JARDIM, J. G.; MELLO, B. L. B.; GORIA, L. S.; DERESZ, F.;VIEIRA, R. A. M.; ROHEM JR., N. M.Avaliação do modelo NRC para predição do consumo de matéria seca por vacas leiteiras manejadas em pastagens tropicais. In: REUNIÃO ANUAL DA SOCIEDADE BRASILEIRA DE ZOOTECNIA, 49, 2012, Brasília. Anais... Brasília: SBZ, 2012.

LEGGI, S.S.C.T.; SANTOS,T.G.; FURLAN, C.A.; SAKAGUTI,S.E.; RIBAS, P.N.; MIRA, T.R.; VEIGA, R.D.; BETT, V. Utilização do farelo de canola (Brassica napus) na alimentação de vacas leiteiras. Revista Brasileira de Zootecnia, v.27, n.4, p.770-776, 1998.

LOPES, C.F.F.; AROEIRA, M.J.L.; RODRIGUEZ, N.M.; SAMPAIO, M.B.I.;DERESZ, F.; BORGES, I.; BERCHIELLI, T.T.Predição do Consumo de Pasto de Capim-Elefante (Pennisetum purpureum, Schumack) por Vacas Mestiças Holandês x Zebu em Lactação. Revista Brasileira de Zootecnia, v.34, n.3, p.1017-1028, 2005.

MARTINEZ, C.J.Avaliação de coprodutos na alimentação de vacas leiteiras mantidas em pastagens tropicais durante a estação chuvosa e alimentadas no cocho durante a estação seca do ano. 2008. 352f. Tese (Doutorado em Agronomia) Universidade de São Paulo, Piracicaba.
MCMENIMAN, P.J.;DEFOOR, P.J.; GALYEAN, L.M. Evaluation of the national research council (1996) dry matter intake prediction equations and relationships between intake and performance by feedlot cattle. Journal of Animal Science, v.87, p.1138-1146, 2009.

MELO, S.A.A.; FERREIRA,A.M.; VERÁS, C.S.A.; LIRA, A.M.; LIMA, E.L.; VILELA, S.M.; MELO, S.O.E.; ARAÚJO, B.R.P. Substituição parcial do farelo de soja por uréia e palma forrageira (Opuntia ficus indica mill) em dietas para vacas em lactação. I. Desempenho. Revista Brasileira de Zootecnia, v.32, n.3, p.727-736, 2003.

MENDONÇA, S.S. Consumo, digestibilidade aparente, produção e composição do leite e variáveis ruminais em vacas leiteiras alimentadas com dietas à base de cana-de-açúcar.

Revista Brasileira de Zootecnia, v.33, n.2, p.481-492, 2004.

MERTENS, R.D.Predicting intake and digestibility using mathematical models of ruminal function. Journal of Animal Science, v.64, p.1548-1558, 1987.

MERTENS, D.R. Regulation of forage intake. In: FAHEY JUNIOR., G.C., (Ed.). Forage quality, evaluation and utilization. Madison: American Society of Agronomy, 1994. p.450-493.

\section{MONTGOMERY, C.D. Design and} analysis of experiments. 6.ed. Nova Iorque. John Wiley \& Sons, 2005. 643 p.

NATIONAL RESEARCH COUNCIL NRC. Nutrient requirements of dairy cattle. 6. ed. Washington, DC: National Academic Press, 1989. 157p. 
NATIONAL RESEARCH COUNCIL NRC. Nutrient requirements of beef cattle. 7.ed.Washington: National Academy Press, 1996.

NATIONAL RESEARCH COUNCIL NRC. Nutrient requeriments of dairy cattle. 7. ed. Washington: National Academy Press, 2001.

NETO, J.F.; REIS, R.B.; SAMPAIO, M.B.I.; SATURNINO,H.M.; SOUSA, M.B.; MOREIRA, M.E. Produção e composição do leite de vacas alimentadas com cana de açúcar suplementada com fontes de nitrogênio não proteico de diferentes degradabilidades ruminal. Revista ARS Veterinária, v.29, n.1, p.052-059, 2013.

OLIVEIRA, S.A.; VALADARES, D.F.R.; VALADARES, F.C.S.; CECON, R.P.; OLIVEIRA, S.A.G.; NUNES, M.R.; COSTA, L.A.M. Consumo, digestibilidade aparente, produção e composição do leite em vacas alimentadas com quatro níveis de compostos nitrogenados não-protéicos.

Revista Brasileira de Zootecnia, v.30, n.4, p.1358-1366, 2001.

OLIVEIRA, S.A.; CAMPOS, S.M.J.; FILHO, V.C.S.; ASSIS, J.A.;

TEIXEIRA, A.M.R.; VALADARES, D.F. R.; PINA, S.D.; OLIVEIRA, S.G.

Substituição do milho por casca de café ou de soja em dietas para vacas leiteiras: consumo, digestibilidade dos nutrientes, produção e composição do leite. Revista Brasileira de Zootecnia, v.36, n.4, p.1172-1182, 2007.

PEREIRA, A.L.M.; FILHO, V.C.S.; VALADARES, D.F.R.; CAMPOS, S.M.J.; LEÃO, I.M.; PEREIRA, R.A.C.; SILVA, A.P.;MENDONÇA, S.S. Consumo, digestibilidade aparente total, produção e composição do leite em vacas no terço inicial da lactação alimentadas com níveis crescentes de proteína bruta no concentrado. Revista Brasileira de Zootecnia, v.34, n.3, p.1029-1039, 2005.

PIRES, V.A.; SUSIN, I.; SIMAS, C.M.J; JÚNIOR, O.C.R.; FERNANDES, R.J.J.; ARAUJO, C.R.; MENDES, Q.C. Substituição de silagem de milho por cana-de-açúcar e caroço de algodão sobre o desempenho de vacas holandesas em lactação.

Revista Ciência Animal Brasileira, v.11, n.2, p.251-257, 2010.

RAMALHO, P.R.; FERREIRA, A.M.; VÉRAS, C.S.A.; SANTOS, C.D.; CAVALCANTI, A.C.V.; ROCHA, A.V.R.R.Substituição do farelo de soja pela mistura raspa de mandioca e uréia em dietas para vacas mestiças em lactação. Revista Brasileira de Zootecnia, v.35, n.3, p.1212-1220, 2006.

REZENDE, P.L.P.; NETO, M.D.F.; RESTLE, J.; FERNANDES, J.J.R.; PÁDUA, J.T.; QUEIROZ, G.A.B.Validação de modelos matemáticos para predição de consumo voluntário e ganho em peso de bovinos, Arquivos de Zootecnia, v.60, n.232, p.921 - 930, 2011.

RENNÓ, F.P.; PEREIRA, J.C.; SANTOS, A.D.F.; ALVES, N.G.; TORRES, C.A.A.; RENNÓ, L.N.; BALBINOT, P.Z. Efeito da condição corporal ao parto sobre a produção e composição do leite, a curva de lactação e a mobilização de reservas corporais em vacas da raça Holandesa. Arquivo Brasileiro de Medicina Veterinária e Zootecnia, v.58, n.2, p.220-233, 2006. 
RIBEIRO, S.J.; LADEIRA, M.M.;

NETO, M.R.O.;

CAMPOS,R.F.Consumo alimentar e sua predição pelos sistemas NRC, CNCPS e BR-Corte, para tourinhos zebuínos confinados.Revista Ciência

Agronômica, Fortaleza, v.43, n.4, p. 802-810, 2012.

SANTOS, V.F.M.; FARIAS, I.; LIRA, A.M.; NASCIMENTO, A.M.M.; SANTOS,C.D.; FILHO, T.J.J.Colheita da palma forrageira (Opuntia ficus indica mill) cv. gigante sobre o desempenho de vacas em lactação.

Revista Brasileira de Zootecnia, v.27, n.1, p.33-39, 1998.

SANTOS, D.F.A.; TORRES, A.C.A.; RENNÓ, P.F.; DRUMOND, S.R.M.; JÚNIOR, F.E.J.Utilização de óleo de soja em rações para vacas leiteiras no período de transição: consumo, produção e composição do leite.

Revista Brasileira de Zootecnia, v.38, n.7, p.1363-1371, 2009.

SANTOS, B.A.; PEREIRA, A.L.M.; AZEVEDO, T.S.; SIGNORETTI, D.R.; SIQUEIRA, R.G.; MENDONÇA, S.S.; PIRES, V.J.A.; PEREIRA, J.C.T.; ALMEIDA, J.P.P.; RIBEIRO, O.S.L.; PEREIRA' R.A.C.Vacas lactantes alimentadas com silagem de cana-deaçúcar com e sem aditivo bacteriano: consumo, digestibilidade, produção e composição do leite. Revista Brasileira de Saúde e Produção Animal [online], v.13, n.3, p. 720-731, 2012.

SILVA, N.M.R.;

VALADARES,D.F.R.; FILHO, V.C.S.; CECON, R.P.; CAMPOS, M.S.J.' OLIVEIRA, A.G.; OLIVEIRA, S.A.Uréia para vacas em lactação. 1. Consumo, digestibilidade, produção e composição do leite. Revista Brasileira de Zootecnia, v.30, n.5, p.1639-1649, 2001 .
SOARES, A.C.; CAMPOS, S.M.J.; FILHO, V.C.S.; VALADARES, F.D.R.; MENDONÇA, S.S.; QUEIROZ, C.A.; LANA, P.R.Consumo, digestibilidade aparente, produção e composição do leite de vacas leiteiras alimentadas com farelo de trigo. Revista Brasileira de

Zootecnia, v.33, n.6, p.2161-2169, 2004.

SOUSA, C.C. Modelos para predição do consumo de matéria seca e produção de leite por vacas, Scientific Journal of Animal production, v.11, n.2, p.94-102, 2009.

SOUZA, M.C.; OLIVEIRA, A.S. ; ARAÚJO, C.V. ; BRITO, A.F. ; TEIXEIRA, R.M.A. ; MOARES, E.H.B.K. ; MOURA, D.C. . Short communication: Prediction of intake in dairy cows under tropical conditions.

Journal of Dairy Science, v. 97, p.1-10, 2014.

TYLUTKI, T. P.; FOX, D. G.; DURBAL, V. M.; TEDESCHI, L. O.; RUSSELL, J. B.; VAN AMBURGH, M. E.; OVERTON, T. R.; CHASE, L. E., PELL, A. N.. Cornell Net Carbohydrate and Protein System: A model for precision feeding of dairy cattle. Animal Feed Science and Technology, v.143, p.174-202, 2008.

VASORI, V.E.; LUCCI, S.C.; PIRES, L.F.; ARCARO, P.R.J.; ARCARO JÚNIOR, I.Avaliação da cana-de-açucar em substituição a silagem de milho para vacas leiteiras. Revista Brasileira de pesquisa Veterinária e Ciência Animal, v.32. n.4, p.224-225,1995.

VIEIRA, M.A.R.; CAMPOS, S.S.R.P.; SILVAE, C.F.J.; TEDESCHI, O.L.; TAMY, T.W. Heterogeneity of the insoluble fiber os selected forages in situ. Animal Feed Science and Technology, v.171, n.2, p.154-166, 2012. 
VILELA, S.M.;FERREIRA, A.M.;

VÉRAS, C.S.A.; SANTOS, F.V.M.;

FARIAS, I.; MELO, S.A.A.;

RAMALHO, P.R.; ARAÚJO,

B.R.P.Avaliação de diferentes

suplementos para vacas mestiças em

lactação alimentadas com cana-de-

açúcar: desempenho e digestibilidade.

Revista Brasileira de Zootecnia, v.32, n.3, p.768-777, 2003.

WIRBELT, A.C. Glicerina bruta na alimentação de vacas leiteiras. 2012. 163f. Tese (Doutorado em Zootecnia), Programa de Pós-graduação em Zootecnia - Universidade Federal do Rio Grande do Sul, Porto Alegre.

Data de recebimento: 22/09/2015

Data de aprovação: 02/12/2016 